\title{
Hubungan Tingkat Pengetahuan tentang ASI Eksklusif dengan Pemberian ASI Eksklusif pada Wanita Pekerja di Subang
}

\author{
Annisa Aulia Listiani, ${ }^{1}$ Siska Nia Irasanti, ${ }^{2}$ Zulmansyah, ${ }^{3}$ Eka Nurhayati, ${ }^{2}$ Budiman ${ }^{2}$ \\ ${ }^{1}$ Program Studi Pendidikan Dokter, Fakultas Kedokteran, ${ }^{2}$ Bagian Ilmu Kesehatan Masyarakat, ${ }^{3}$ Bagian Anak, \\ Universitas Islam Bandung,
}

\begin{abstract}
Abstrak
Peningkatan jumlah pekerja perempuan terutama berada pada usia reproduksi sering menjadi kendala bagi mereka untuk memberikan ASI eksklusif sehingga pemberian ASI eksklusif sering tidak tercapai. Tujuan penelitian ini adalah mengetahui hubungan antara tingkat pengetahuan tentang ASI eksklusif dan pemberian ASI eksklusif pada wanita pekerja pabrik di PT Taekwang Subang. Penelitian ini merupakan penelitian kuantitatif bersifat observasional analitik dengan pendekatan cross sectional. Pengumpulan data diambil dari hasil kuesioner yang telah tervalidasi. Subjek penelitian adalah wanita yang sedang bekerja di pabrik PT Taekwang bagian divisi produksi bottom (proses bagian bawah sepatu) dan produksi upper (proses bagian atas sepatu) yang mempunyai bayi usia $\geq 6-24$ bulan dengan jumlah subjek penelitian sebanyak 93 orang. Data penelitian dianalisis dan diuji menggunakan uji chisquare. Dari hasil penelitian didapatkan bahwa jumlah responden sebagian besar memberikan ASI eksklusif sebanyak 51 responden (55\%) dan yang tidak memberikan ASI eksklusif sebanyak 42 responden (45\%) hal tersebut memiliki perbedaan yang tidak jauh berbeda. Hasil analisis chi-squre dengan statistical product and service solution (SPSS), nilai p yang didapatkan 0,48 lebih besar dari alpha yang telah ditentukan 0,05. Dari hasil penelitian ini dapat disimpulkan bahwa tidak terdapat hubungan tingkat pengetahuan tentang ASI eksklusif dengan pemberian ASI eksklusif pada wanita pekerja pabrik PT Taekwang Subang.
\end{abstract}

Kata kunci: ASI eksklusif, tingkat pengetahuan, wanita pekerja

\section{Related between Exclusive Breastfeeding Knowledge and Exclusive BreastFeeding on FemaleWorker in Subang}

\begin{abstract}
Increasing numbers of female worker primarily in the reproductive age is often a constraint for them to give exclusive breastfeeding. Many of them then decide not to give exclusive breastfeeding for their babies. The purpose of this study was to assess the relation between knowledge about exclusive breastfeeding with exclusive breastfeeding behavior on female worker in PT Taekwang Subang. This study was a quantitative analytic observational research with cross sectional approach. Data collected by validated questionnaire. Subjects were women who work at bottom and upper production division (bottom and upper of shoe process) in PT Taekwang factor who had babies aged z6-24 months, totally 93 subjects. Research data were analyzed and tested using chi-square test. The study showed that the respondents who gave exclusive breastfeeding (55\%) with those who did not give exclusive breastfeeding (45\%) had not spesific differences. chi-square analysis with statistical product and service solution (SPSS), p-value obtained 0.48 greater than the specified alpha 0.05. In conclution, there is no relation between mother's about exclusive breastfeeding and exclusive breastfeeding on female worker in PT Taekwang Subang.
\end{abstract}

Key words: Exclusive breastfeeding, knowledge, female worker

Korespondensi: Annisa Aulia Listiani. Prodi Pendidikan Sarjana Kedokteran, Fakultas Kedokteran, Universitas Islam Bandung, Jalan Taman Sari No. 22, 40116, Kota Bandung, Provinsi Jawab, Hp: 081220062416 Email: Listianiannisa@ymail.com 


\section{Pendahuluan}

Air susu ibu (ASI) makanan paling sempurna bagi bayi. Pemberian ASI bermanfaat bagi asupan zat-zat bergizi bernilai tinggi yang dibutuhkan untuk pertumbuhan dan perkembangan saraf dan otak bayi, memberikan zat-zat kekebalan terhadap beberapa jenis penyakit, serta mewujudkan ikatan emosional antara ibu dan bayi. Begitu pentingnya manfaat ASI eksklusif bagi bayi sehingga World Health Organization (WHO) merekomendasikan agar ibu menyusui bayinya selama 6 bulan. ${ }^{1}$

Berdasar atas data Profil Kesehatan Indonesia tahun 2016 cakupan pemberian ASI eksklusif bagi bayi usia 0-6 bulan pada 2016 di Indonesia sebesar 29\%. Prevalensi cakupan pemberian ASI eksklusif di Jawa Barat sebesar 39\%, salah satunya di Kabupaten Subang sebesar 39\% dengan target program pada tahun 2016 sebesar 42\%. Berdasar atas data tersebut dapat disimpulkan bahwa cakupan pemberian ASI di Kabupaten Subang masih rendah. ${ }^{2}$

Survei Demografi Kesehatan Indonesia (SDKI) tahun 2012 menunjukkan 55\% wanita di Indonesia merupakan wanita pekerja dan sebagian besar berada pada usia yang reproduksi. ${ }^{4}$ Data-data yang diperoleh dari Tim Relawan Pengkaji Informasi Publik/TRPIP Kabupaten Subang menunjukkan 21 perusahaan yang bergerak dalam industri dan menyerap \pm 36.504 tenaga kerja, sebanyak $84 \%$ adalah perempuan. ${ }^{5}$ Perusahaan tersebut salah satunya adalah PT Taekwang Industrial Indonesia (PT TII) Subang.

Pekerjaan sering kali menjadi kendala bagi wanita untuk memberikan ASI eksklusif sehingga pemberian ASI eksklusif sering tidak tercapai. Faktor-faktor yang menghambat keberhasilan menyusui pada ibu bekerja adalah waktu cuti kerja yang singkat, kurangnya dukungan tempat kerja, waktu istirahat singkat setelah bekerja, tidak ada ruangan untuk memerah ASI, serta pertentangan keinginan ibu antara mempertahankan prestasi kerja dan produksi ASI. ${ }^{3}$

Penelitian ini bertujuan mengetahui hubungan tingkat pengetahuan dengan pemberian ASI eksklusif pada wanita pekerja khususnya wanita pekerja pabrik di PT Taekwang Subang.

\section{Metode}

Penelitian merupakan penelitian kuantitatif bersifat observasional analitik dengan cara pendekatan crosssectional. Populasi dalam penelitian ini adalah seluruh wanita yang sedang bekerja di pabrik PT Taekwang Subang yang mempunyai bayi usia $\geq 6-24$ bulan. Penelitian ini berlangsung sejak bulan Maret sampai Juni 2018 di PT Taekwang Subang.

Subjek penelitian berjumlah 93 orang serta data dipilih berdasar atas kriteria inklusi dan eksklusi. Kriteria inklusinya adalah pekerja tetap pabrik PT Taekwang bagian divisi produksi bottom dan upper yang mempunyai bayi usia 6-24 bulan, serta dapat membaca dan juga menulis. Kriteria eksklusi adalah wanita yang memiliki riwayat penyakit pada payudara seperti kanker payudara, tumor payudara, infeksi atau peradangan payudara, serta responden yang tidak ingin menyusui.
Pemilihan sampel dipilih dengan menggunakan teknik simple random sampling yang dilaksanakan dengan cara undian. Besar sampel dalam penelitian ini dihitung mempergunakan formula uji hipotesis beda 2 proporsi (analitik komparatif kategorik tidak berpasangan).

Rumus sampel:

$$
n=\frac{\left(z_{1-\alpha / 2} \sqrt{2 \bar{P}(1-\bar{P})}+z_{1-\beta} \sqrt{P_{1}\left(1-P_{1}\right)+P_{2}\left(1-P_{2}\right)}\right)^{2}}{\left(P_{1}-P_{2}\right)^{2}}
$$

dari hasil perhitungan didapat nilai $n=93$ responden.

Variabel penelitian terdiri atas tingkat pengetahuan tentang ASI eksklusif dan pemberian ASI eksklusif. Tingkat pengetahuan mengenai ASI itu dikategorikan menjadi 3 tingkatan, yaitu kurang, cukup, dan baik. Pengumpulan data diambil dengan menggunakan alat ukur berupa kuesioner. Kuesioner yang digunakan terdiri atas 8 item pertanyaan tentang pengetahuan ASI eksklusif, 9 item pertanyaan tentang pemberian ASI eksklusif, serta 6 item tentang fasilitas laktasi di ruang kerja.

Penelitian diawali dengan melakukan penyebaran kuesioner. Data-data yang sudah terkumpul kemudian diolah dengan komputerisasi. Langkah yang pertama dalam pengolahan data adalah editing seluruh data yang sudah terkumpul diperiksa terlebih dahulu. Selanjutnya, adalah coding, yaitu dari data yang telah dilakukan pengeditan kemudian dilakukan pemberian kode yang sesuai klasifikasi data yang telah ditentukan. Kemudian, entry memindahkan data dari kuesioner ke dalam master tabel dan yang terakhir adalah cleaning, yaitu pembersihan data atau melakukan pengecekan ulang data kemudian dianalisis menggunakan uji chi -square. Penelitian ini mendapatkan kajian etik dari Komite Etik Penelitian Kesehatan Fakultas Kedokteran Universitas Islam Bandung Nomor: 188/Komite Etik. FK/III/2018.

\section{Hasil}

Hasil penelitian mengenai distribusi data berdasar atas pendidikan, pengetahuan, dan pemberian ASI eksklusif disajikan dalam Tabel 1.

\section{Tabel 1 Distribusi Frekuensi Responden}

\begin{tabular}{|c|c|c|c|}
\hline \multicolumn{2}{|l|}{ Variabel } & \multirow{2}{*}{$\begin{array}{c}\mathbf{n}=\mathbf{9 3} \\
12\end{array}$} & \multirow{2}{*}{$\begin{array}{l}\% \\
13\end{array}$} \\
\hline Pendidikan & $\mathrm{SD}$ & & \\
\hline & SMP & 32 & 34 \\
\hline & SMA & 48 & 52 \\
\hline & PT & 1 & 1 \\
\hline \multirow[t]{3}{*}{ Pengetahuan } & Kurang & 4 & 4 \\
\hline & Cukup & 41 & 44 \\
\hline & Baik & 48 & 52 \\
\hline \multirow[t]{2}{*}{ Pemberian ASI eksklusif } & $\mathrm{Ya}$ & 42 & 45 \\
\hline & Tidak & 51 & 55 \\
\hline
\end{tabular}

Sumber: Data primer 2018 
Tabel 1 memperlihatkan bahwa tingkat pendidikan responden yang terbanyak adalah SMA (52\%). Tingkat pengetahuan responden tentang ASI eksklusif yang paling tinggi adalah tingkat pengetahuan baik sebanyak 28 dari 48 responden (58\%). Frekuensi responden yang memberikan ASI eksklusif dengan yang tidak memberikan ASI eksklusif memiliki perbedaan yang tidak jauh berbeda.

\begin{tabular}{|c|c|c|c|c|c|}
\hline Tabel 2 & \multicolumn{5}{|c|}{$\begin{array}{l}\text { Hubungan Tingkat Pengetahuan tentang } \\
\text { ASI Eksklusif dengan Pemberian ASI } \\
\text { Eksklusif pada Wanita Pekerja Pabrik PT } \\
\text { Taekwang Subang }\end{array}$} \\
\hline \multirow{3}{*}{\multicolumn{2}{|c|}{$\begin{array}{c}\text { Tingkat } \\
\text { Pengetahuan }\end{array}$}} & \multicolumn{2}{|c|}{ ASI Eksklusif } & \multirow{3}{*}{$\begin{array}{l}\text { Total } \\
\mathbf{n}=\mathbf{9 3}\end{array}$} & \multirow{3}{*}{ Nilai p } \\
\hline & & Tidak & Ya & & \\
\hline & & $\mathbf{n}=\mathbf{5 1}$ & $n=42$ & & \\
\hline Kurang & & 3 & 1 & 4 & \multirow{3}{*}{0,48} \\
\hline Cukup & & 20 & 21 & 41 & \\
\hline Baik & & 28 & 20 & 48 & \\
\hline
\end{tabular}

Sumber: Data Primer 2018

Responden yang tidak memberikan ASI eksklusif (51 orang) terdapat 28 responden (48\%) mempunyai tingkat pengetahuan yang baik. Berdasar atas uji chisquare, nilai p yang didapatkan $(0,48)$ lebih besar daripada alpha yang ditentukan $(0,05)$ berarti tidak terdapat hubungan tingkat pengetahuan tentang ASI eksklusif dengan pemberian ASI eksklusif.

\section{Pembahasan}

Penelitian yang dilaksanakan terhadap 93 responden menunjukkan tingkat pengetahuan ibu tentang ASI eksklusif yang bekerja di PT Taekwang Subang sebagian besar memiliki pengetahuan baik. Pengetahuan atau kognitif merupakan dominan sangat penting dalam membentuk tindakan seseorang. 6

Tingkat pengetahuan tinggi yang disajikan dalam Tabel 1 disebabkan oleh beberapa faktor di antaranya adalah pendidikan. Keadaan ini sejalan dengan teori yang menyatakan bahwa semakin tinggi pendidikan seseorang maka akan semakin mudah pula menerima informasi serta semakin banyak pengetahuan yang dimiliki sehingga memengaruhi perilaku seseorang. ${ }^{6}$ Faktor lain yang memengaruhi tingkat pengetahuan adalah sosial, budaya, ekonomi, informasi atau media masa, pengalaman, lingkungan, dan usia. ${ }^{7}$ Berdasar atas hasil penelitian ini tidak terdapat hubungan antara tingkat pengetahuan tentang ASI eksklusif dan pemberian ASI ekslusif pada wanita pekerja pabrik PT Taekwang Subang.

Hal ini sesuai dengan penelitian yang dilakukan oleh Usman dkk. ${ }^{8}$ bahwa tidak terdapat hubungan antara pengetahuan dan pemberian ASI eksklusif. Hal ini disebabkan oleh kesamaan karakteristik responden. Populasi dalam penelitian ini adalah seluruh ibu yang memiliki bayi usia 7-12 bulan dan berstatus pekerja sebagai perawat dengan tingkat pendidikan tinggi. Status pekerjaan ibu merupakan faktor yang dapat memengaruhi pemberian ASI eksklusif. ${ }^{8}$
Mayoritas pengetahuan responden baik, namun tidak memberikan ASI eksklusif disebabkan oleh ibu yang bekerja akan menghadapi beberapa kendala dalam memberikan ASI eksklusif kepada bayinya, antara lain adalah alokasi waktu, kualitas kebersamaan dengan bayi, beban kerja, stres, dan keyakinan ibu untuk memberikan ASI eksklusif akan terpengaruh. Faktor lain, yaitu banyak kantor atau institusi kerja tidak mendukung program untuk pemberian ASI, tidak ada upaya penyiapan ruangan khusus untuk tempat menyusui atau memompa ASI, serta kurang dukungan keluarga. Menurut Sudiharto seperti dikutip Syafneli dan Handayani ${ }^{9}$ dukungan keluarga itu mempunyai hubungan dengan suksesnya pemberian ASI eksklusif kepada bayi. Dukungan keluarga adalah dukungan untuk memotivasi ibu memberikan ASI saja kepada bayinya sampai usia 6 bulan, memberikan dukungan psikologis kepada ibu, dan mempersiapkan nutrisi yang seimbang kepada ibu.

Kondisi ini semakin diperburuk dengan peraturan cuti yang hanya berlangsung selama 3 bulan membuat banyak ibu seharusnya mempersiapan bayinya dengan makanan pendamping ASI sebelum masa cutinya habis maka pemberian ASI eksklusif menjadi tidak berhasil. Keadaan ini sejalan dengan peraturan ketenagakerjaan di PT Taekwang Subang yang diatur dalam UU No. 13 Tahun 2003 tentang Ketenagakerjaan yang berlaku di Indonesia dengan menggunakan aturan shif kerja.

Peraturan shif kerja di PT Taekwang Subang terdiri atas shif pagi dimulai pada pukul 07.00-15.00, shift siang dimulai 15.00-22.00, dan shif malam dimulai pukul 22.00-07.00 dengan jumlah jam kerja pada shif malam mencapai 8 jam. Hal ini menjadi hambatan karena tidak terdapat kebijakan pemberian shif pagi sampai bayi berusia 6 bulan bagi ibu menyusui. Selain hal tersebut, saat malam hari waktu istirahat yang singkat serta lokasi fasilitas ruang laktasi yang jauh akan lebih dimanfaatkan ibu untuk beristirahat. ${ }^{10}$

Peraturan ini tidak sejalan dengan rekomendasi WHO yang mensyaratkan pemberian ASI eksklusif selama enam bulan. Dalam pasal 128 ayat 2 dan 3 Undang-Undang Republik Indonesia No: 36 Tahun 2009 tentang Kesehatan dinyatakan bahwa selama pemberian ASI, pihak keluarga, pemerintah daerah, dan masyarakat harus mendukung ibu secara penuh dengan penyediaan waktu seta fasilitas khusus. ${ }^{10}$

Ruang menyusui yang dimiliki oleh PT Taekwang dapat digunakan oleh pengunjung maupun karyawan untuk menyusui atau memerah ASI. Berdasar atas hasil observasi, ruang menyusui tersebut terletak di klinik PT TKII dengan ukuran ruangan lebih kurang 4x5 m². Ruangan tersebut cukup luas dan nyaman, terdapat sebuah sofa, kursi rapat, beberapa poster mengenai menyusui, satu buah kipas angin, dan satu freezer. Hal yang menjadi kendala karena jarak dari tempat kerja responden dengan ruang laktasi yang jauh sehingga hal ini dapat menjadikan salah satu hambatan dalam pemberian ASI eksklusif.

Penelitian ini berbeda dengan penelitian Fitri Yulianti $^{11}$ di wilayah kerja Puskesmas Siantan Hulu Pontianak yang memperlihatkan terdapat hubungan antara pengetahuan ibu dan pemberian ASI eksklusif. Status pekerjaan responden dalam penelitian tersebut dibagi dalam dua kelompok, yaitu tidak bekerja dan 
bekerja. Berdasar atas hal tersebut diperoleh bahwa responden dalam penelitian tersebut sebagian besar sebagai ibu rumah tangga (tidak bekerja) 77\% dengan sebagian besar tingkat pengetahuan dalam kategori kurang sebanyak $48 \%$ dengan tingkat pendidikan sekolah dasar terbanyak, yaitu 58\%.

Terjadiperbedaan hasil penelitian dapat disebabkan oleh perbedaan jumlah status pekerjaan responden serta tingkat pendidikan. Banyaknya responden yang tidak bekerja akan berdampak terhadap pengetahuan dan pemberian ASI eksklusif. Pemberian ASI eksklusif pada wanita pekerja lebih kecil dibanding dengan ibu rumah tangga dikarenakan pada wanita pekerja dapat menyita waktu dan juga mengurangi jatah pemberian ASI eksklusif kepada bayinya, sedangkan pada ibu rumah tangga lebih mempunyai banyak waktu untuk memberikan ASI eksklusif. ${ }^{11}$

Penelitian ternyata sejalan dengan hasil penelitian yang dilaksanakan oleh Septyasrini ${ }^{12}$ bahwa terdapat hubungan antara tingkat pengetahuan ASI eksklusif dan pemberian ASI eksklusif dengan jumlah status responden terbanyak adalah ibu rumah tangga (tidak bekerja) dibanding dengan ibu bekerja. Hal ini terjadi karena kedua penelitian tersebut mempunyai jumlah status bekerja responden yang sama.

\section{Simpulan}

Berdasar atas penelitian yang sudah dilakukan dapat disimpulkan tidak terdapat hubungan antara tingkat pengetahuan tentang ASI eksklusif dan pemberian ASI eksklusif pada wanita pekerja pabrik di PT Taekwang Subang.

\section{Ucapan Terima Kasih}

Ucapan terima kasih kepada Epi Slamet selaku GA manager PT Taewang, staf PT Taekwang, tenaga kesehatan di klinik PT Taekwang, serta semua pihak yang telah banyak membantu proses pengumpulan data dalam penyusunan artikel ini.

\section{Daftar Pustaka}

1. WHO | Exclusive breastfeeding. WHO [homepage on Internet]. 2017 [diunduh 14 Februari 2018]. Tersedia dari: http://www.who.int/nutrition/ topics/exclusive_breastfeeding/en/

2. Hardhana B, Budiono CS, Kurniasih N, Manullang EV, Susanti MI, Pangribowo S, dkk. Data dan informasi profil kesehatan Indonesia 2016.
Jakarta: Kemenkes RI; 2017.

3. Aisyaroh N, Sutrisminah E, Islam U, Agung S. Evaluasi fasilitas ruang ASI dalam implementasi kebijakan pemberian ASI eksklusif pada buruh perempuan di perusahaan tekstil Jawa Tengah. Universitas Muhammadiyah Semarang [serial on the Internet]. 2017 [diunduh 13 Februari 2018]. Tersedia dari: http://jurnal.unimus.ac.id/index. php/psn12012010/article/viewFile/2872/2791.

4. BPS. Jumlah tenaga kerja perempuan di Indonesia. [serial on the Internet]. 5 Juni 2017 [diunduh 24 Desember 2017]. Tersedia dari: http://independen.id/read/data/429/jumlahtenaga-kerja-perempuan-di-indonesia/.

5. Budian Yusuf. Apa dan siapa tim relawan pengkaji informasi publik (TRPIP) Subang? - KOTASUBANG.com [serial on the Internet]. 12/03/2016. 2016 [diunduh 19 Januari 2018]. Tersedia dari: https://www.kotasubang. com/7844/apa-dan-siapa-tim-relawan-pengkajiinformasi-publik-trpip-subang7.

6. Notoatmodjo S. Ilmu perilaku kesehatan. Jakarta: Rineka Cipta: 2010.

7. Budiman AR. Kapita selekta kuesioner: pengetahuan dan sikap dalam penelitian kesehatan. Jakarta: Salemba Med; 2013.

8. Usman LY, Umboh JML, Lestari H. Faktorfaktor yang berhubungan dengan pemberian ASI eksklusif di wilayah kerja Puskesmas Bahuu Kecamatan Malalayang Kota Manado. $\mathrm{CH}$. 2017;2(1):1-12.

9. Syafneli, Handayani EY. Analisis faktor-faktor yang berhubungan dengan pemberian ASI eksklusif di Desa Pasir Jaya tahun 2014. J Matern Neonatal. 2015;2(1):54-61.

10. UU Nomor 13 Tahun 2003 tentang Ketenagakerjaan. 2007 [diunduh 18 Januari 2018]. Tersedia dari: http://prokum.esdm.go.id/ uu/2003/uu-13-2003.pdf.

11. Fitri Yulianti. Hubungan antara karakteristik, tingkat pengetahuan dan dukungan keluarga terhadap pemberian ASI eksklusif di wilayah kerja Puskesmas Siantan Hulu Kecamatan Pontianak Utara tahun 2014. [diunduh 6 Juli 2018]. Tersedia dari: https://media.neliti.com/media/ publications/193267-ID-hubungan-antarakarakteristik-tingkat-pe.pdf.

12. Septyasrini N. Hubungan antara tingkat pengetahuan dan status pekerjaan dengan pemberian ASI eksklusif di wilayah kerja Puskesmas Banyudono 1 Boyolali [diunduh 6 Juli 2018]. Tersedia dari: http://eprints.ums. ac.id/44706/1/10. Naskah Publiaksi.pdf. 